\title{
Intraepithelial lymphocytes subsets in different forms of celiac disease
}

\author{
M. Sánchez-Castañon ${ }^{1} \cdot$ B. G. Castro ${ }^{2} \cdot$ M. Toca ${ }^{1}$ C. Santacruz ${ }^{1}$. \\ M. Arias-Loste ${ }^{2} \cdot$ P. Iruzubieta $^{2} \cdot$ J. Crespo $^{2} \cdot$ Marcos López-Hoyos $^{1}$
}

Received: 10 June 2016/ Accepted: 6 September 2016/Published online: 23 September 2016

(C) The Author(s) 2016. This article is published with open access at Springerlink.com

\begin{abstract}
Aim The enumeration of intraepithelial lymphocytes subsets (total, $\gamma \delta$, and $\mathrm{CD}^{-}$IELs) by flow cytometry (FCM), named as IEL lymphogram, constitutes a useful tool for celiac disease (CD) diagnosis. The aim of this study was to quantify IELs by FCM and their diagnostic value to differentiate active, silent and potential CD.

Methods Prospective study of 60 active and 20 silent CD patients, and 161 controls in which duodenal biopsy and IEL quantification by FCM was performed.

Results Active and silent CD patients had significant higher levels of both total and $\gamma \delta$ IELs than absent CD patients $(P<0.0001$ and $P<0.0001, P=0.012$ and $P<0.011$; respectively). Active and silent CD patients had significant lower levels of $\mathrm{CD}^{-}$IELs than absent $\mathrm{CD}$ patients $(P<0.047$ and $P<0.009$, respectively). Moreover, they were lower in silent than in active CD patients $(P=0.002)$. Changes of IELs subsets were more marked in children than adults active CD. The optimal IEL lymphogram cut off values for active CD diagnosis were: $\geq 10$, $\geq 15$ and $\leq 9 \%$, and with better performance characteristics for silent CD: $\geq 11, \geq 10$ and $\leq 5 \%$.

Conclusion The evaluation of IELs subsets by FCM is useful to confirm diagnosis of active and silent CD.
\end{abstract}

Keywords Intraepithelial lymphocytes - Flow cytometry · Active celiac disease $\cdot$ Silent celiac disease

Marcos López-Hoyos

mlopezhoyos@humv.es

1 Immunology Section, Hospital Universitario Marqués de Valdecilla-IDIVAL, 39008 Santander, Spain

2 Gastroenterology Service, Hospital Universitario Marqués de Valdecilla-IDIVAL, Santander, Spain

\section{Introduction}

Celiac disease (CD) is an autoimmune enteropathy induced by gluten in genetically predisposed patients and characterized by intestinal inflammation with lymphocytic intraepithelial infiltration and villous atrophy [1].

Intraepithelial lymphocytes (IELs) represent an abundant and heterogeneous population of antigen-experienced $\mathrm{T}$ cells that reside in the intestinal epithelium. They are composed of T cells bearing the $\alpha \beta$ ( $\alpha \beta$ IELs $>90 \%$ ) or the $\gamma \delta \mathrm{T}$ cell receptor $(\gamma \delta$ IELs $<10 \%)$. Additionally, the epithelium of healthy intestinal mucosa contains a significant proportion of $\mathrm{CD}^{-} \mathrm{CD}^{-} 103^{+}$IELs (CD3 ${ }^{-}$IELs) [2].

It has been reported that IELs are increased in the duodenal/jejunum mucosa of untreated CD patients and would represent the earliest feature even seen when the villous architecture is preserved. Consequently, they alone can constitute the first sign of latent or potential forms of CD [3-6]. However, it can also be found in other autoimmune disorders, viral infections and diverse gastrointestinal diseases, such as small intestinal bacterial overgrowth (SIBO), tropical sprue, microscopic colitis, inflammatory bowel disease, irritable bowel syndrome (IBS) and allergic enteritis. Therefore, increased IELs are considered a hallmark of $\mathrm{CD}$, although not disease-specific $[2,7]$.

Besides, increased $\gamma \delta$ IELs can be found in the intestinal epithelium of both treated and untreated CD patients, and they are considered highly sensitive and specific for all the forms of CD. However, they are not pathognomonic, because they are also found in cow milk-sensitive enteropathy, food allergy, Crohn's disease, post-enteritis syndrome, cryptosporidiasis and IgA-deficiency [8-11]. On the other hand, $\mathrm{CD}^{-}$IELs are present in healthy duodenal mucosa and disappear in active CD [12-15]. Therefore, 
quantification of both $\gamma \delta$ and CD $3^{-}$IELs confers specificity to the finding of increased IELs observed in CD patients $[12,16]$. Thus, the enumeration of IELs and the immunophenotyping of IELs subsets (total, $\gamma \delta$, and $\mathrm{CD}^{-}$ IELs) by flow cytometry (FCM), named IEL lymphogram, constitute useful diagnostic tools for CD diagnosis but also to evaluate the activity of the disease and to identify atypical (latent and potential CD) and even asymptomatic forms (silent $\mathrm{CD}$ ) [6].

The aim of this prospective study was to evaluate the diagnostic performance of quantifying the IELs subsets (total, $\gamma \delta$, and $\mathrm{CD}^{-}$IELs) by FCM in patients with active and silent $\mathrm{CD}$, and to study differences between children and adults with active $\mathrm{CD}$ from a referral university hospital.

\section{Methods}

This prospective study involved 231 patients with clinical suspicion for CD who underwent a duodenal biopsy and serologic studies for $\mathrm{CD}$ at the Pediatrics and the Gastroenterology outpatient clinics at the "Hospital Universitario Marques de Valdecilla" between June 2008 and April 2012. The work has been carried out in accordance with the local Ethics Committee. Clinical and histological data were collected from information contained in medical records.

We subdivided patients according to the type of $\mathrm{CD}$ into the following groups: active $\mathrm{CD}(n=60)$ and silent $\mathrm{CD}$ $(n=20)$. We have also included 161 patients without CD (absent $\mathrm{CD}$ ) in whom biopsy and serum tests were performed, as control group.

The diagnosis of CD was based on ESPGHAN and AGA criteria. The diagnosis of active $\mathrm{CD}$ required the presence of the classical symptoms of malabsorption, positive serology [anti-recombinant human tissue transglutaminase (TTG) and anti-gliadin (AGA, whole gliadin extract) IgA or IgG antibodies], as well as compatible histopathology and HLA-DQ2 and/or -DQ8. The diagnosis of silent CD was made in asymptomatic patients (with positive serology and villous atrophy).

The combined study of total, $\gamma \delta$, and $\mathrm{CD} 3^{-}$IELs, termed IEL lymphogram, was performed by FCM in all patients. A single biopsy specimen was obtained for FCM analysis at the same time of diagnostic endoscopy for histological analysis. The sample was kept in physiologic saline solution, and immediately processed using a previously described protocol with minor modifications [17]. Briefly, IEL and epithelial cells were liberated from the mucosal specimens by mechanical disaggregation. The suspension of released cells was collected by centrifugation, washed and surface labelled with the appropriate fluorochrome-conjugated monoclonal antibodies (mAbs): CD45-PerCP, CD3-FITC, TcR $\gamma \delta$-PE and CD103-PE (BD
Biosciences, San Diego, CA). Data were acquired in a FACSCalibur (BD Biosciences) and analyzed with Cell Quest software (BD Biosciences). IEL cells were selected from the entire cell population of epithelial cells after gating on the basis of their low side scattering and CD45 expression (Fig. 1).

Duodenal biopsies were categorized according to Marsh classification as modified by Oberhuber et al. [14]. Lesions were further divided into two categories: mild, including increased intraepithelial lymphocytes, crypt hyperplasia, or mild villous atrophy (Marsh I, II, and IIIa); and severe, with marked villous atrophy, subtotal and total (Marsh IIIb and IIIc).

\section{Statistical analysis}

Statistical analysis was carried out with the use of SPSS software (version 13, SPSS, Chicago, IL). All data were expressed as median \pm interquartile range (IQR).

Differences in the percentage of the three IELs subsets (total, $\gamma \delta$ and $\mathrm{CD}^{-}$) among the different groups of $\mathrm{CD}$ and between children and adults active $\mathrm{CD}$ patients were calculated by the Mann-Withney $U$ non-parametric test. This test was also used to calculate differences in the degree of histopathological lesions between the different groups of $\mathrm{CD}$ and between children and adults active $\mathrm{CD}$.

The correlation among serum autoantibodies and total, $\gamma \delta$ and $\mathrm{CD}^{-}$IELs frequencies in active and silent $\mathrm{CD}$ patients were calculated by the Spearman rho test. $P$ values $<0.05$ were considered significant.

A receiver operator characteristic (ROC) curve analysis associated with the Youden index was carried out to determine the optimal cut off $(\mathrm{CO})$ values for the combination of total, $\gamma \delta$ and $\mathrm{CD}^{-}$IELs counts (IEL lymphogram) that could be used for the diagnosis of active, silent and potential CD. Diagnostic capacity was considered failed when area under the ROC curves (AUC) results

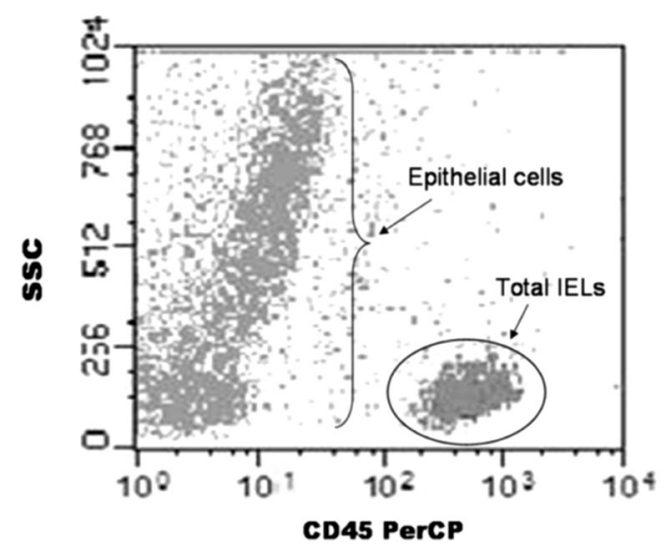

Fig. 1 Selection of total IELs respect to the total cellularity of the duodenal epithelium, on the basis of their low $90^{\circ}$ light scattering and CD45 expression 
were $<0.5$. The diagnostic value of IEL lymphogram was calculated as sensitivity, specificity, positive predictive value (PPV) and negative predictive value (NPV).

\section{Results}

\section{Patient characteristics}

The general characteristics of the patients included in the study are summarized in the Table 1 . Among the 60 patients with active CD, 49 were children ( $82 \%$, female $/$ male ratio $=1.6: 1)$ and 11 were adults $(18 \%$, female/male ratio $=4.5: 1)$. However, from the patients with silent and absent $\mathrm{CD}, 3$ out of $20(15 \%$, female/male ratio $=2: 1)$, and 11 out of $161 \quad(7 \%$, female/male ratio $=1.6: 1)$ were children, respectively.

\section{IELs subsets counts in the different types of celiac disease}

The median percentage of total IELs was significantly higher in both active $\mathrm{CD}$ and silent $\mathrm{CD}$ patients than in patients with absent CD. No significant differences were found among active and silent CD patients (Fig. 2a).

The median percentage of $\gamma \delta$ IELs was also significantly higher in both active $\mathrm{CD}$ and silent $\mathrm{CD}$ patients than in patients with absent $C D$. No significant differences were found among active and silent CD patients (Fig. 2b).

The mean percentage of $\mathrm{CD}^{-}$IELs was significantly lower in both active $\mathrm{CD}$ and silent $\mathrm{CD}$ than in patients with absent CD. Moreover, it was significantly lower in silent CD than in active $\mathrm{CD}$ (Fig. 2c).

\section{IELs subsets counts in children and adult active celiac disease}

Children had more total and $\gamma \delta$ IELs $(18 \pm 22$ and $27 \pm 19 \%$, respectively) than adult active CD patients (11 \pm 22 and $15.5 \pm 14.5 \%$, respectively), although no significant differences were found among the groups $(P=0.176$ and $P=0.088$, respectively). On the contrary, the counts of $\mathrm{CD}^{-}{ }^{-}$IELs were significantly lower in adult than in children active CD patients $(4 \pm 7$ vs. $8 \pm 13 \% ; P=0.008)$.

Table 1 General characteristics of patients included in the study

\begin{tabular}{lrcl}
\hline & \multicolumn{1}{c}{$n$} & \multicolumn{1}{c}{ Age* } & Sex (male/female) \\
\hline Active celiac disease & 60 & $9(1-63)$ & $21 / 39$ \\
Silent celiac disease & 20 & $36(12-62)$ & $7 / 13$ \\
Absent celiac disease & 161 & $42(5-84)$ & $58 / 103$ \\
\hline
\end{tabular}

* Data are expressed as mean years (range)
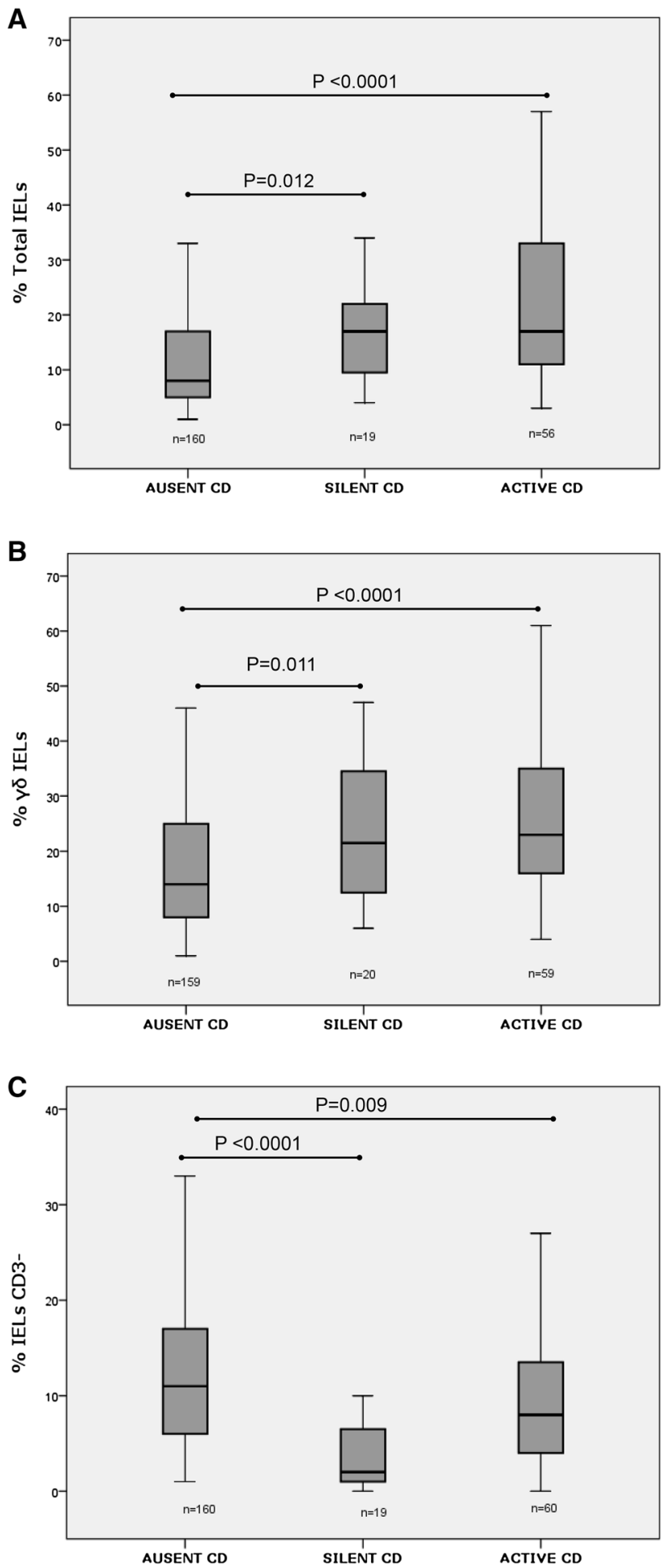

\section{IELs and histopathology}

The frequency of severe histopathology was significantly higher in patients with active $\mathrm{CD}(69 \%)$ than in silent $\mathrm{CD}$ (35\%; $P=0.007)$. Severe active CD patients had higher levels of total IELs, $\gamma \delta$ IELs and CD $3^{-}$IELs as compared 
4Fig. 2 a Percentage of total IELs respect to the total cellularity of the duodenal epithelium in the study groups. Box plots with median, quartiles and 5 and 95 percentiles. $U$ de Mann-Whitney test was used to detect significant differences $(P<0.05)$. b Percentage of $\gamma \delta$ IELs relative to the total number of IELs in the study groups. Box plots show median, quartiles and 5 and 95 percentiles. $U$ de Mann-Whitney test was used to detect significant differences $(P<0.05)$. c Percentage of $\mathrm{CD}^{-}$IELs relative to the total number of IELs in the study groups. Box plots show median, quartiles and 5 and 95 percentiles. $U$ de Mann-Whitney test was used to detect significant differences $(P<0.05)$

with mild active $\mathrm{CD}$ patients. No significant differences were found in silent CD patients (Table 2).

\section{IELs and serological markers}

The frequency of positive AGA IgA was similar in active (72\%) or silent CD patients $(60 \%)$, with no differences according to patients age (Tables 3,4$)$. On the other hand, the frequency of positive TTG IgA was higher in active CD patients than in silent $\mathrm{CD}$ patients (87 vs. $70 \%$, no significant differences).

As serum levels of TTG IgA increased, a linear tendency toward higher $\gamma \delta$ IELs counts in active CD patients
(Spearman $\rho=0.422, \quad P=0.002$ ) and more severe histopathological lesions (Spearman $\rho=0.393$, $P=0.003$ ) were observed. On the contrary, no correlation was found in silent $\mathrm{CD}$ patients.

\section{ROC curve for the IELs subsets in the diagnosis of active and silent $\mathrm{CD}$}

From the ROC curve analysis performed of IEL lymphogram in active $C D$ diagnosis showed that the optimal $\mathrm{CO}$ values for the percentages of total, $\gamma \delta$ and $\mathrm{CD} 3^{-}$IELs were: $\geq 10 \%$ (sensitivity $=82 \%$ and specificity $=59 \%$, AUC $=0.725), \geq 15 \%$ (sensitivity $=76 \%$ and specificity $=53 \%, \quad$ AUC $=0.696) \quad$ and $\leq 9 \% \quad$ (sensitivity $=67 \%$ and $\quad$ specificity $=57 \%, \quad$ AUC $=0.614)$, respectively.

The optimal $\mathrm{CO}$ values for the percentage of total, $\gamma \delta$ and $\mathrm{CD}^{-}$IELs for silent CD diagnosis were: $\geq 11 \%$ (sensitivity $=74 \% \quad$ and $\quad$ specificity $=60 \%$, AUC $=0.673$ ), $\geq 10 \%$ (sensitivity $=95 \%$ and specificity $=33 \%, \quad$ AUC $=0.663)$ and $\leq 5 \% \quad$ (sensitivity $=74 \%$ and $\quad$ specificity $=79 \%, \quad$ AUC $=0.836$ ), respectively.
Table 2 IELs populations and histopathology in active and silent CD
Table 3 Serological markers in celiac disease

\begin{tabular}{|c|c|c|c|}
\hline Active CD & $\begin{array}{l}\text { Mild histopathology } \mathrm{y}^{\mathrm{a}} \\
(n=18)\end{array}$ & $\begin{array}{l}\text { Severe histopathology } \\
(n=40)\end{array}$ & $P$ value* \\
\hline$\%$ Total IELs & $17.29 \pm 14.28$ & $25.95 \pm 15.21$ & $0.027 *$ \\
\hline$\% \gamma \delta$ IELs & $21.22 \pm 14.28$ & $29.44 \pm 15.08$ & $0.031 *$ \\
\hline$\% \mathrm{CD}^{-}$IELs & $11.36 \pm 19.57$ & $11.62 \pm 9.77$ & $0.027 *$ \\
\hline Silent CD & $\begin{array}{l}\text { Mild histopathology } \\
(n=13)\end{array}$ & $\begin{array}{l}\text { Severe histopathology } \\
(n=7)\end{array}$ & $P$ value* \\
\hline$\%$ Total IELs & $16.85 \pm 7.29$ & $14.00 \pm 9.53$ & 0.628 \\
\hline$\% \gamma \delta$ IELs & $22.54 \pm 12.93$ & $31.57 \pm 19.89$ & 0.234 \\
\hline$\% \mathrm{CD}^{-}$IELs & $5.19 \pm 6.35$ & $2.61 \pm 3.17$ & 0.562 \\
\hline
\end{tabular}

Data are expressed as mean \pm standard deviation

$C D$ celiac disease

* Significant differences $(P<0.05)$

${ }^{a}$ Mild histopathology: Marsh I, II, and IIIa

b Severe histopathology: Marsh grade IIIb and IIIc

\begin{tabular}{lccc}
\hline & AGA IgA ${ }^{\mathrm{a}}$ & TTG IgA ${ }^{\mathrm{b}}$ & AGA IgA+ and TTG IgA+ \\
\hline Active celiac disease & $74(40 / 54)$ & $87(47 / 54)$ & $67(36 / 54)$ \\
Silent celiac disease & $60(12 / 20)$ & $70(14 / 20)$ & $55(11 / 20)$ \\
Absent celiac disease & $1(2 / 156)$ & $0(0 / 156)$ & $0(0 / 156)$ \\
\hline
\end{tabular}

Data are expressed as percentage (number of positive cases/total number of cases)

$A G A \operatorname{IgA}$ anti-gliadin $\operatorname{IgA}$ antibodies, TTG IgA anti-recombinant human tissue transglutaminase $\operatorname{IgA}$

${ }^{a} \mathrm{AGA} \operatorname{IgA}+\geq 20 \mathrm{UI} / \mathrm{L}$

b TTG $\mathrm{IgA}+\geq 4 \mathrm{UI} / \mathrm{L}$ 
Table 4 Serological markers in children and adult celiac disease

\begin{tabular}{lccc}
\hline & AGA IgA ${ }^{\mathrm{a}}$ & TTG IgA $^{\mathrm{b}}$ & AGA IgA+ and TTG IgA+ \\
\hline Children $(<18$ years $)$ & $77(33 / 43)$ & $91(39 / 43)$ & $70(30 / 43)$ \\
Active celiac disease & $67(2 / 3)$ & $100(3 / 3)$ & $67(2 / 3)$ \\
Silent celiac disease & $0(0 / 13)$ & $0(0 / 13)$ & $0(0 / 13)$ \\
Absent celiac disease & & & \\
Adult $(\geq 18$ years $)$ & $64(7 / 11)$ & $73(8 / 11)$ & $55(6 / 11)$ \\
Active celiac disease & $59(10 / 17)$ & $65(11 / 17)$ & $53(9 / 17)$ \\
Silent celiac disease & $0(0 / 143)$ & $0(0 / 143)$ & $0(0 / 143)$ \\
Absent celiac disease & & & \\
\hline
\end{tabular}

Data are expressed as percentage (number of positive cases/total number of cases)

$A G A \operatorname{IgA}$ anti-gliadin $\operatorname{Ig}$ A antibodies, TTG IgA anti-recombinant human tissue transglutaminase $\operatorname{IgA}$

a $\mathrm{AGA} \operatorname{IgA}+\geq 20 \mathrm{UI} / \mathrm{L}$

b TTG $\mathrm{IgA}+\geq 4 \mathrm{UI} / \mathrm{L}$

\section{ROC curve for the IELs subsets in the diagnosis of children and adult active $C D$}

The ROC curve analysis performed on the IEL subsets for the children active $\mathrm{CD}$ diagnosis showed that the optimal $\mathrm{CO}$ values for the percentage of total, $\gamma \delta$ and $\mathrm{CD}^{-}$IELs were: $\geq 10 \%$ (sensitivity $=87 \%$ and specificity $=62 \%$, AUC $=0.715), \geq 15 \%$ (sensitivity $=82 \%$ and specificity $=77 \%, \quad$ AUC $=0.832$ ) and $\leq 9 \% \quad$ (sensitivity $=63 \%$ and specificity $=61 \%, \quad$ AUC $=0.612$ ), respectively. Whereas for adult active $\mathrm{CD}$ patients were: $\geq 10 \% \quad$ (sensitivity $=60 \%$ and specificity $=58 \%$, AUC $=0.587$ ), $\geq 10 \%$ (sensitivity $=90 \%$ and specificity $=31 \%, \quad$ AUC $=0.547)$ and $\leq 4 \% \quad$ (sensitivity $=64 \%$ and specificity $=80 \%, \quad$ AUC $=0.798)$, respectively.

\section{Diagnostic value of IEL lymphogram for active and silent $\mathrm{CD}$ diagnosis}

Table 5 shows the sensitivity, specificity, PPV and NPV of the optimal IEL lymphogram (total, $\gamma \delta$, and $\mathrm{CD}^{-}$IELs counts) for active and silent CD diagnosis.

In this study, the optimal IEL lymphogram for silent CD diagnosis (total IELs $\geq 11 \%, \gamma \delta$ IELs $\geq 10 \%$ and $\mathrm{CD}^{-}$ IELs $\leq 5 \%$ ) had higher sensitivity, specificity and NPV than the IEL lymphogram for active CD diagnosis (total IELs $\geq 10 \%, \gamma \delta$ IELs $\geq 15 \%$ and $\mathrm{CD}^{-}$IELs $\leq 9 \%$ ). However, the PPV of IEL lymphogram was higher for active $\mathrm{CD}$ than for silent $\mathrm{CD}$ diagnosis (52 vs. $44 \%$ ).

\section{Discussion}

$\mathrm{CD}$ is an immune-mediated enteropathy caused by an abnormal immune response to dietary gluten proteins, characterized by altered IELs pattern.

Camarero et al. [13] have developed a FCM technique for the evaluation of IELs subsets in intestinal biopsies of CD patients. Three main alterations have been described in CD patients. First, total IELs are increased during the active phases of the disease [3-6, 18]. Second, which could be considered practically pathognomonic, there is a permanent increase in $\gamma \delta$ IELs $[19,20]$, observed in every form of the disease $[8,13,21]$, and it could constitute the first sign of latent or potential forms of CD [9]. Finally, there is a pronounced and constant decrease in $\mathrm{CD}^{-}$IELs, which become virtually undetectable in active $\mathrm{CD}$ $[12,23-25]$. Since those changes in IEL subsets are very characteristic of $\mathrm{CD}$, the analysis by FCM of the 3 parameters (total, $\gamma \delta$ and $\mathrm{CD}^{-}$IELs), and termed "IEL
Table 5 Diagnostic value of optimal IEL lymphogram for active and silent $\mathrm{CD}$

\begin{tabular}{lllll}
\hline & $\begin{array}{l}\text { Sensitivity } \\
(\%)\end{array}$ & $\begin{array}{l}\text { Specificity } \\
(\%)\end{array}$ & $\begin{array}{l}\text { PPV } \\
(\%)\end{array}$ & $\begin{array}{l}\text { NPV } \\
(\%)\end{array}$ \\
\hline $\begin{array}{l}\text { Optimal IEL lymphogram in active CD } \\
(\geq 10, \geq 15 \text { and } \leq 9 \%)\end{array}$ & 45 & 86 & 52 & 82 \\
$\begin{array}{l}\text { Optimal IEL lymphogram in silent CD } \\
(\geq 11, \geq 10 \text { and } \leq 5 \%)\end{array}$ & 56 & 92 & 44 & 95 \\
\hline
\end{tabular}

IEL lymphogram: total, $\gamma \delta$ and $\mathrm{CD}^{-}$IELs

$I E L$ intraepithelial lymphocytes, $C D$ celiac disease, $P P V$ positive predictive value, $N P V$ negative predictive value 
lymphogram" has been described to be of high specificity and sensitivity in the diagnosis of $\mathrm{CD}$, even of atypical forms [6].

In this study we have evaluated the profile of IELs in a long cohort of patients with active and silent CD. According to other authors, we have also found a significant increase of both total and $\gamma \delta$ IELs and a significant decrease of CD3- IELs in active CD patients as compared to patients with absent $\mathrm{CD}[13,16,19,22,26]$. Interestingly, we have observed similar alterations on IELs subsets in silent CD patients. Our results are in discordance with the study of Erias et al. [27] that reported the same IEL lymphograms in patients with active, latent and potential $\mathrm{CD}$, and suggested that the IELs lymphogram may be particularly useful for the diagnosis of latent and potential CD. In the same way, Goldstein et al. [28] suggested that increased IELs could constitute, by themselves, the first sign of latent or potential forms of $\mathrm{CD}$, even in the presence of preserved villi. Moreover, several authors reported that potential CD was characterized by an increased number of total and/or $\gamma \delta$ IELs [9, 13, 21, 27]. From our data, the evaluation of the IELs subsets may be of help as diagnostic tool in active and silent $\mathrm{CD}$, but we do not have conclusive data on potential CD.

Besides, we have compared the IELs subsets in children and adults active CD patients. Accordingly with the study of Calleja et al. [26], we have also found more pronounced changes on IELs subsets in children than in adult active CD patients, suggesting that the determination of IELs subsets may be particularly useful for the diagnosis of active $\mathrm{CD}$ in children.

Of note, we have observed that the increase of total and $\gamma \delta$ IELs was higher in active CD patients with severe histopathology than in those with mild histopathology. Moreover, we have found that as serum levels of TTG IgA increase there is a linear tendency toward more severe histopathological lesions and higher $\gamma \delta$ IELs counts. These data are in agreement with previous reports [29-32], which described that TTG IgA levels are correlated with the degree of histopathological lesions in CD patients. However, our results are in disagreement with previous studies $[8,13,21,26]$, which reported that the density of $\gamma \delta$ IELs was not correlated with the degree of intestinal tissue damage and that there was an increase on the density of $\gamma \delta$ IELs in all stages of $\mathrm{CD}$, including latent and potential CD patients. These authors suggest that the evaluation of $\gamma \delta$ IELs could be used as a diagnostic marker to identify early stage CD. Our data may reflect that in patients with more active disease, represented by more severe histopathology and higher levels of TTG IgA, there are more abnormalities in IELs subsets, mainly $\gamma \delta$ IELs.

Finally, the optimal IEL lymphogram set in the present study for silent CD diagnosis (total IELs $\geq 11 \%, \gamma \delta$ IELs $\geq 10 \%$ and $\mathrm{CD}^{-}$IELs $\leq 5 \%$ ) had better diagnostic performance than that set for active CD diagnosis (total IELs $\geq 10 \%, \gamma \delta$ IELs $\geq 15 \%$ and $\mathrm{CD}^{-}$IELs $\leq 9 \%$ ).

In conclusion, our results indicate that the evaluation of IELs subsets by FCM could be useful to confirm diagnosis of active and silent $\mathrm{CD}$.

\section{Acknowledgments}

Financial support María Sánchez Castañón is a recipient of a Lopez Albo grant from the IDIVAL. This work has been partially supported by grants from IDIVAL (CI 10/52, CI 13/10).

\section{Compliance with ethical standards}

\section{Conflict of interest None.}

Ethical approval All procedures performed in studies involving human participants were in accordance with the ethical standards of the institutional and/or national research committee and with the 1964 Helsinki declaration and its later amendments or comparable ethical standards.

Informed consent All subjects gave their written informed consent for the endoscopy study within the clinical routine of the hospital. The study of intraepithelial lymphocytes is performed as a routine test at our center and there is no specific consent from for the study.

Open Access This article is distributed under the terms of the Creative Commons Attribution 4.0 International License (http://crea tivecommons.org/licenses/by/4.0/), which permits unrestricted use, distribution, and reproduction in any medium, provided you give appropriate credit to the original author(s) and the source, provide a link to the Creative Commons license, and indicate if changes were made.

\section{References}

1. Rostom A, Murray JA, Kagnoff MF (2006) American Gastroenterological Association (AGA) Institute technical review on the diagnosis and management of celiac disease. Gastroenteroly 31:1981-2002

2. Abadie V, Discepolo V, Jabri B (2012) Intraepithelial lymphocytes in celiac disease immunopathology. Semin Immunopathol 34:551-566

3. Biagi F, Luinetti O, Campanella J, Klersy C, Sambelli C, Villanacci $\mathrm{V}$ et al (2004) Intraepitelial lymphocytes in the villous tips: do they indicate potential coeliac disease? J Clin Pathol 57:835-839

4. Mäki M, Holm K, Collin P, Savilahti E (1991) Increase in gamma/delta $\mathrm{T}$ cell receptor bearing lymphocytes in normal small bowel mucosa in latent coeliac disease. Gut 32:1412-1414

5. Mahadeva S, Wyatt JI, Howdle PD (2002) Is a raised intraepithelial lymphocyte count with normal duodenal villous architecture clinically relevant? J Clin Pathol 55:424-428

6. Camarero C, León F, Sánchez L, Asensio A, Roy G (2007) Agerelated variation of intraepithelial lymphocytes subsets in normal human duodenal mucosa. Dig Dis Sci 52:685-691

7. Walker MM (2011) Murray JA An update in the diagnosis of coeliac disease. Histopathology 59:166-179

8. Savilahti E, Arato A, Verkasalo M (1990) Intestinal gamma/delta receptor bearing $\mathrm{T}$ lymphocytes in celiac disease and 
inflammatory bowel diseases in children. Constant increase in celiac disease. Pediatr Res 28:579-581

9. Maki M, Holm K, Collin P, Savilahti E (1991) Increase in gamma/delta $\mathrm{T}$ cell receptor bearing lymphocytes in normal small bowel mucosa in latent coeliac disease. Gut 32:1412-1414

10. Spencer J, Isaacson PG, MacDonald TT, Thomas AJ, WalkerSmith JA (1991) Gamma/delta $T$ cells and the diagnosis of coeliac disease. Clin Exp mmunoly 85:109-113

11. Jarvinen TT, Kaukinen K, Laurila K, Kyronpalo S, Rasmussen M, Maki M (2003) Intraepithelial lymphocytes in celiac disease. Am J Gastroenterol 98:1332-1337

12. Eiras P, Roldan E, Camarero C, Olivares F, Bootello A, Roy G (1998) Flow cytometry description of a novel CD3- CD7+ intraepithelial subset in human duodenal biopsies: potential diagnostic value in coeliac disease. Cytometry 34:95-102

13. Camarero C, Eiras P, Asensio A, León F, Escobar H, Roy G (2000) Intraepithelial lymphocytes and coeliac disease: permanent changes in $\mathrm{CD}^{-} / \mathrm{CD}^{+}$and $\mathrm{T}$ cell receptor $\gamma \delta$ subsets studied by flow cytometry. Acta Paediatr 89:285-290

14. Leon F, Roy G (2004) On the complexity of human CD3intraepithelial lymphocytes. Gastroenterology 126:1217-1218

15. Gunter U, Holloway JA, Gordon JG, Knight A, Chance V, Hanley NA et al (2005) Phenotypic characterization of $\mathrm{CD}^{-} 7+$ cells in developing human intestine and an analysis of their ability to differentiate into T cells. J Immunol 174:5414-5422

16. Leon F, Eiras P, Roy G, Camarero C (2002) Intestinal intraepithelial lymphocytes and anti-transglutaminase in screening algorithm for coeliac disease. Gut 50:740-774

17. Madrigal L, Lynch S, Feighery C, Weir D, Kelleher D, O'Farrelly CJ (1993) Flow cytometry analysis of surface major histocompatibility complex class II expression on human epithelial cells prepared from small intestinal biopsies. J Immunol Meth 158:207-214

18. Schuppan D (2000) Current concepts of celiac disease pathogenesis. Gastroenterology 119:234-242

19. Verkasalo MA, Arató A, Savilahti E, Tainio VM (1990) Effect of diet and age on jejunal and circulating lymphocyte subsets in children with coeliac disease: persistence of $\mathrm{D}^{-} 8^{-}$intraepithelial T cells through treatment. Gut. 31:422-425

20. Spencer J, Isaacson PG, Diss TC, MacDonald TT (1989) Expression of disulfide-linked and non-disulfide-linked forms of the $\mathrm{T}$ cell receptor gamma/delta heterodimer in human intestinal intraepithelial lymphocytes. Eur J Immunol. 19:1335-1338

21. Holm K, Maki M, Savilahti E, Lipsanen V, Laippala P, Koskimies S (1992) Intraepithelial gamma delta T-cell-receptor lymphocytes and genetic susceptibility to coeliac disease. Lancet 339:1500-1503
22. Spencer J, MacDonald TT, Diss TC, Walker-Smith JA, Ciclitira PJ, Isaacson PG (1989) Changes in intraepithelial lymphocyte subpopulations in coeliac disease and enteropathy associated $\mathrm{T}$ cell lymphoma (malignant histiocytosis of the intestine). Gut. 30:339-346

23. Hadziselimovic F, Emmons LR, Schaub U, Signer E, BürginWolff A, Krstic R (1992) Occurrence of large granular lymphocytes and natural killer cells in the epithelium of the gut distinguishes two different coeliac diseases. Gut. 33:767-772

24. León F, Camarero C, Eiras P, Roy G (2004) Specificity of IEL profiling in the diagnosis of celiac disease. Am J Gastroenterol. 99:958

25. Grose RH, Thompson FM, Cummins AG (2008) Deficiency of 6B11+ invariant NK T-cells in celiac disease. Dig Dis Sci. 53:1846-1851

26. Calleja S, Vivas S, Santiuste M, Arias L, Hernando M, Nistal E et al (2011) Dynamics of Non-conventional Intraepithelial Lymphocytes-NK, NKT, and $\gamma \delta \mathrm{T}$-in Celiac Disease: Relationship with Age, Diet, and Histopathology. Dig Dis Sci 56:2042-2049

27. Eiras P, León F, Camarero C, Roy G (2002) Los linfocitos intraepiteliales en el diagnóstico de la enfermedad celíaca latentepotencial. Rev Clin Esp 202:497-499

28. Goldstein NS (2004) Non-gluten sensitivity-related small-bowel villous flattening with increased intraepithelial lymphocytes: not all that flattens is celiac sprue. Am J Clin Pathol 121:546-550

29. Barker CC, Mitton C, Jevon G, Mock T (2005) Can tissue transglutaminase antibody titers replace small-bowel biopsy to diagnose celiac disease in select pediatric populations? Pediatrics 115:1341-1346

30. Donaldson MR, Firth SD, Wimpee H, Leiferman KM, Zone JJ, Horsley W et al (2007) Correlation of duodenal histology with tissue transglutaminase and endomysial antibody levels in pediatric celiac disease. Clin Gastroenterol Hepatol 5:567-573

31. Dahlbom I, Korponay-Szabó IR, Kovács JB, Szalai Z, Mäki M et al (2010) Prediction of clinical and mucosal severity of coeliac disease and dermatitis herpetiformis by quantification of $\operatorname{IgA} / \mathrm{IgG}$ serum antibodies to tissue transglutaminase. J Pediatr Gastroenterol Nutr 50:140-146

32. Klapp G, Masip E, Bolonio M, Donat E, Polo B, Ramos D et al (2013) Celiac disease: the new proposed ESPGHAN diagnostic criteria do work well in a selected population. J Pediatr Gastroenterol Nutr. 56:251-256 